\title{
Research on the Protection of Vulnerable Groups in Water Pollution Conflicts Based on Binomial Tree Pricing Model
}

\author{
Yanping Chen*, Tiejun Cheng, Fengping Wu \\ Business School, Hohai University, Nanjing, China \\ Email: ${ }^{*}$ chenyp@hhu.edu.cn
}

Received 26 March 2015; accepted 27 June 2015; published 30 June 2015

Copyright (C) 2015 by authors and Scientific Research Publishing Inc.

This work is licensed under the Creative Commons Attribution International License (CC BY). http://creativecommons.org/licenses/by/4.0/

cc) (i) Open Access

\begin{abstract}
The interests of vulnerable groups can't be guaranteed due to their weaker capacity and the limited interests demand channels during the water pollution conflicts. The interest protection for the vulnerable people in the water pollution conflicts has attracted attentions of the international scholars. The paper tries to construct the market mechanism which can make the vulnerable people to involve in the emission trading. The vulnerable people can buy American put option in the emission trading market. When the price of the emission runs below the contract price, the vulnerable people can get the benefit through executing the option. When the price of the emission runs above the contract price, the vulnerable people can give up the right. The binomial tree option pricing model can help the vulnerable people to make a decision through the analysis of the worth of the American put option.
\end{abstract}

\section{Keywords}

Vulnerable Groups, Water Pollution Conflicts, Emission Trading, American Put Option, Binomial Tree Option Pricing Model

\section{Introduction}

Water pollution often causes damages to people's health and wealth. The vulnerable groups should be paid attention due to their weaker capacity and the locked interests demand channels during the water pollution conflicts. When the interests of the vulnerable groups are violated, they are more inclined to adopt an extreme way to protect their interests. However, it will cause conflicts among up-down river districts and have negative ef-

${ }^{*}$ Corresponding author.

How to cite this paper: Chen, Y.P., Cheng, T.J. and Wu, F.P. (2015) Research on the Protection of Vulnerable Groups in Water Pollution Conflicts Based on Binomial Tree Pricing Model. Journal of Water Resource and Protection, 7, 659-664. 
fects on economy development and social stability of the region. In recent years, the water pollution conflicts always happen in China. There are nearly 1700 water pollution accidents every year. The vulnerable groups are the most victims in water pollution conflicts and their interests can't be guaranteed because of weaker capacity.

The international scholars have paid attention to the interest protection of the vulnerable groups in water pollution conflicts. Zhou Jichang (Zhou, 2009) [1] proposed that the victims of China's rural water pollution are in large quantities and wide distribution. Wang Hao et al. proposed that the vulnerable group protection should be considered in water management (Wang et al., 2006) [2]. A. P. Barnes et al. outlined the results of a recent study to understand farmer activities and attitudes towards Nitrate Vulnerable Zone regulations in Scotland (Barnes et al., 2009) [3]. Environmental pollution that renders waters along the coastline and beaches unsatisfactory for use by the general public has become a global health problem (Clark et al., 2003). [4] Chen Yanping and Wu Fengping analyzed the causes of the conflicts and built an evolutionary game model to eliminate the conflicts (Chen and Wu, 2010) [5]. Azizullah Azizullah discussed a detailed layout of drinking water quality in Pakistan with special emphasis on major pollutants, sources of pollution and the consequent health problems (Azizullah et al., 2011) [6]. Shen Dajun focused on the unjust issues existed in water management of China and provided the ways to avoid the unjust issues (Shen, 2005) [7]. Xu and Guo proposed countermeasures for solving water disputes, including integrated management of the river basin, enhancement of legal and regulatory system construction, introduction of market mechanism, and application of new theories about water right and water market to solve water disputes (Xu and Guo, 2007) [8]. Hiromitsu Sakai et al. researched the response patterns of the sensor to the river water quality and pollution (Sakai et al., 2000) [9]. Dong and Li proposed that the demand for water resource is great with the rapid growing of population and expanding industries, and there is an obvious water conflict in the basin (Dong and Li, 2006) [10].

The present research shows that the interest protection of vulnerable groups in water pollution conflicts has attracted the international scholars' attention. To protect the interests of the vulnerable groups, the scholars propose that the government should establish the system of dialogue and negotiation or compensate the vulnerable groups for their loss. As the vulnerable groups are of lower status and have no negotiating power, the protection can't achieve the results. So as to protect the basin environment and promote sustainable development, compensating and protecting vulnerable groups is one of effective means of solving environmental problems and promoting sustainable development. The paper proposes that the vulnerable groups can engage the emission trading market to protect their interest autonomously. The vulnerable peoples can buy the American put option of emission in the emission trading market. When the emission trading price runs below the contract price, the vulnerable people can get the benefits through executing the option. When the emission trading price runs above the contract price, the vulnerable people can give up the right.

The remainder of this paper is organized as follows. In section 2, the concept of emission trading and the assumptions of the model are briefly presented. Section 3 introduces the binomial tree model to protect the interest of vulnerable groups. The application of the model in Tai Basin is introduced in Section 4. Section5 concludes this work.

\section{Assumptions}

The emission trading was introduced by Dales in 1968. The government decides the maximum pollution emissions of the region according to the state of the environment and then divides the Pollution Emissions into sections. Through emission trading, the pollutant in the river basin can be decreased and controlled; the losses of the vulnerable group in water pollution can also be decreased.

In the emission trading market, the increase of the emission trading price will make the polluters pay more for money to discharge pollutants, the polluters may try to develop new technologies or reduce emissions. If the price of the pollution emission decreases, it will make more polluters be able to buy the pollution emission. This will increase the pollutants in the river and cause damage to the vulnerable groups in the water pollution. In this condition, the paper try to introduce the American put option to vulnerable groups to protect their interest through the emission trading market. The vulnerable groups can buy the emission American put option, if the price of the pollution emission decreases, the vulnerable groups can get the benefit through exercising the option. If the price of the pollution emission increases, the vulnerable groups can abandon the option. Although they lose the premium, the pollutants are controlled.

The emission trading price is moving during the certain period of the option. Through the binomial tree option 
pricing model, the period of the option can be divided into several sections, the moving of the price and the value of the option can be analyzed to help the vulnerable groups to make decisions to protect their interest.

The assumptions of the model are as the following:

1) The prices of the pollution emission move according to geometric Brownian motion;

2) The risk neutral pricing theory;

3) The potential for arbitrage means cannot be earned in emission trading;

4) The emission trading and the price move is consecutive;

5) There are no cash flows during the period of the option;

6) Short-selling is permitted in emission trading market.

The model notations are as the following:

$S$ : The present price of the pollution emission;

$T$ : The agreed time of the emission American put option;

$X_{T}$ : The contract price of the pollution;

$\sigma$ : The volatility of the price of the pollution emission;

$r$ : The risk free rate.

\section{Model}

Assume that the vulnerable groups buy an emission American put option in the present time $(t=0)$. The agreed time of the option is $T$. We can divide the $T$ into some small $\Delta t$. Assume that the present value of the emission is $S_{0}$. $S_{1}$ is the value of the option in $t_{1}\left(t_{1}=\Delta t\right)$. If the the vulnerable groups want to assess the value of the option in $t_{1}$, the move of $S_{1}$ can be summarized as the following two states:

$$
\left\{\begin{array}{l}
S_{1}=S^{u}=u S_{0}>S_{0} \\
S_{1}=S^{d}=d S_{0}<S_{0}
\end{array}\right.
$$

We consider $u(u>1)$ as increased factor; it means the emission trading price is comparatively increased. We consider $d(d<1)$ as increased factor; it means the emission trading price is comparatively increased. The probabilities of increasing and decreasing are $p, 1-p$. The move of the price can be described as Figure 1.

If the vulnerable groups want to assess the value of the option in $t_{2}$, the move of $S_{2}$ can be summarized as the following:

$$
\begin{gathered}
t_{1}=\Delta t\left\{\begin{array}{l}
S_{1}=S^{u}=u S_{0}>S_{0} \\
S_{1}=S^{d}=d S_{0}<S_{0}
\end{array}\right. \\
t_{2}=2 \Delta t\left\{\begin{array}{l}
S_{2}=S^{u u}=u^{2} S_{0} \\
S_{2}=S^{u d}=u d S_{0} \\
S_{2}=S^{d u}=u d S_{0} \\
S_{2}=S^{d d}=d^{2} S_{0}
\end{array}\right.
\end{gathered}
$$

In the present time $(t=0)$, the emission trading price is $S_{0}$. In the time $t_{1}$, the emission trading price has two possibilities: $u S_{0}, d S_{0}$. In the time $t_{1}$, the emission trading price has three possibilities: $u^{2} S_{0}, u d S_{0}, d^{2} S_{0}$. In the time $t_{i}=i \Delta t$, the emission trading price has $(i+1)$ possibilities, they are:

$$
u^{j} d^{i-j} S_{0} \quad j=0,1,2, \cdots, i
$$

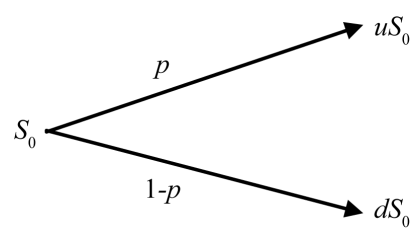

Figure 1. The change of the emission trading price within $\Delta t$ time. 
At the end of the interval $\Delta t$, the expectation of the emission is $\mathrm{e}^{\Delta t} S_{0}$. We can get that:

$$
\begin{gathered}
\mathrm{e}^{\Delta t} S_{0}=p u S_{0}+(1-p) d S_{0} \\
\mathrm{e}^{\Delta t}=p u+(1-p) d
\end{gathered}
$$

The variance of the emission trading price in $\Delta t$ is $S_{0}^{2} \sigma^{2} \Delta t$, we can get:

$$
\begin{gathered}
\sigma^{2} \Delta t S^{2}=p u^{2} S_{0}^{2}+(1-p) d^{2} S_{0}^{2}-[p u+(1-p) d]^{2} S_{0}^{2} \\
\sigma^{2} \Delta t=p u^{2}+(1-p) d^{2}-[p u+(1-p) d]^{2}
\end{gathered}
$$

As $=1 / d$, from Equation (5) and (6), we can get:

$$
\begin{gathered}
p=\frac{a-d}{u-d} \\
u=\mathrm{e}^{\sigma \sqrt{\Delta t}} \\
d=\mathrm{e}^{-\sigma \sqrt{\Delta t}}
\end{gathered}
$$

where $a=\mathrm{e}^{r \Delta t}$ and $\Delta t$ is very small.

The analysis of the binomial tree option pricing model is begun from the end time $T$. As in time $T$, the value of the optionis $\max \left\{\left(X-S_{T}\right), O\right\}$. The vulnerable groups can get the value in time (T- $\left.\Delta t\right)$ through discounting the value of the option of time $T$ at the risk-free rate of interest $r$. In the same way, if we want to get the value in

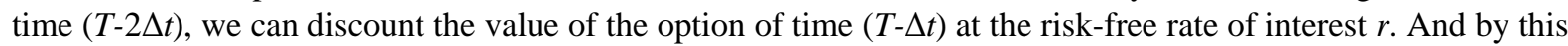
analogy, we can analyze the value of the option at intervals.

The government can subsidize the option premium to vulnerable groups to encourage them to join the emission trading market. The vulnerable groups can buy the emission American put option to protect their interest.

Through the binomial tree option pricing model, the vulnerable groups can analyze the value of the option.

\section{Application}

Emission trading was carried out in Tai Basin by the State Environment Protection Administration at 2008. The platform of Emission trading was gradually achieved. To protect the vulnerable groups in Tai Basin, the government can help them with the premium to encourage the vulnerable groups to engage the marketplace.

In the emission trading market, the vulnerable groups buy the American put option. The duration of the agreement is one year, the emission trading price is $1000 \$$, the executive price is $950 \$$. The volatility of the emission trading price is $20 \%$. The risk free rate is $10 \%$. From the above, we can get that:

$$
S_{0}=1000, \quad X=950, r=0,1, \sigma=0.2, T=1 .
$$

Suppose that the vulnerable groups want to assess the value of the option twice a month. We can divide the duration into six equal intervals.

$$
\text { So, } \Delta t=1.1667, \sqrt{\Delta t}=0.4083 \text {. }
$$

According Equation (9)-(11), we can get as the following:

$$
\begin{gathered}
u=1.0851, d=0.9216, a=1.0168, \\
p=0.5826,1-p=0.4177 .
\end{gathered}
$$

According to the binomial tree option pricing model, we can construct the binomial tree as Figure 2. There are two numbers in every node. The above number stands for the emission trading price, the below number stands for the value of the option.

At time $i \Delta t$, the emission trading price is $u^{j} d^{i-j} S_{0}$ at the node $j$. For example, at the node $E(i=5, j=2)$, the emission trading price is $1.0851^{2} \times 0.9216^{3} \times 1000=921.60$.

We can get the value of the nodes of the penultimate column through that of the last column. Suppose that the option is not performed, and this means the value of the option is the present value of the expected value. For example, the value of the option at the node $F$ is: $(0.5823 \times 0+0.4177 \times 100.65) \times \mathrm{e}^{-0.1 \times 0.1667}=41.35 \$$. The 


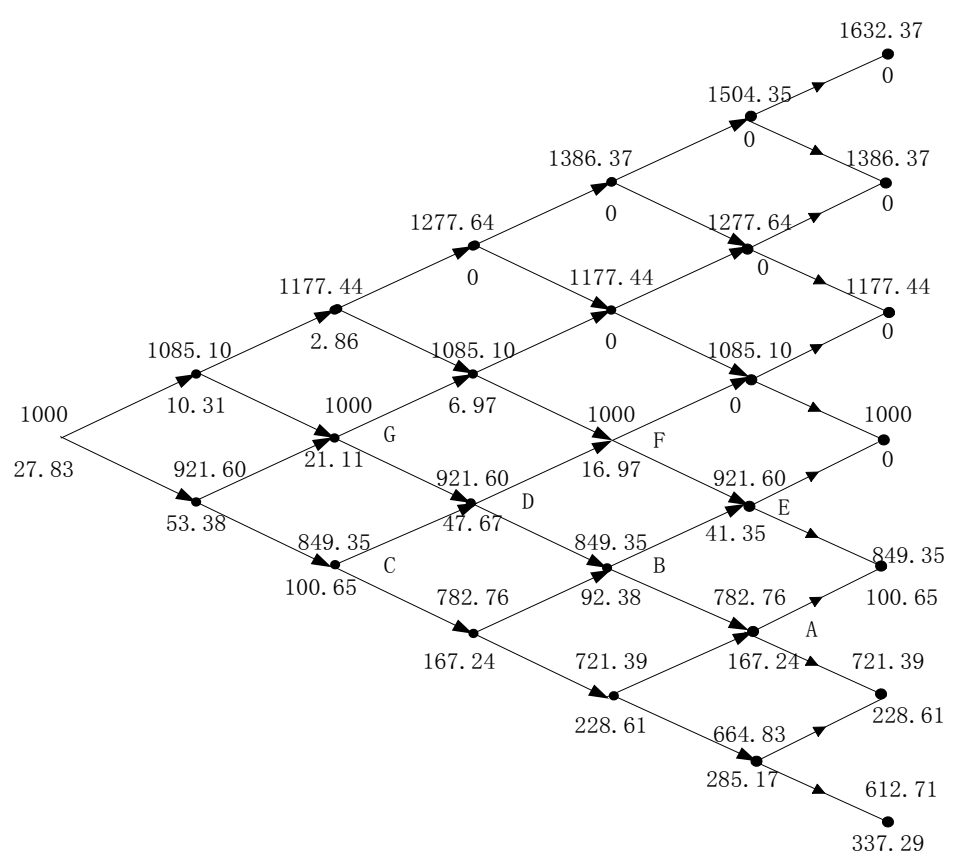

Figure 2. The analysis of the change about the emission price and the option price.

value of the option at the node $A$ is: $(0.5823 \times 100.65+0.4177 \times 228.61) \times \mathrm{e}^{-0.1 \times 0.1667}=151.56 \$$.

The vulnerable groups can make decisions through the binomial tree option pricing model. For example, the value of the option will be 0 at the node $F$ if the vulnerable groups performed the option. So the best choice is to wait. The value of the option at the node $F$ is $10.88 \$$. On the contrary, the choice at the node $A$ is performing the option. Because the value of the option will be $167.24 \$(950-782.76=167.24>151.56)$ at the node $A$ if the vulnerable groups performed the option.

However, performing the option is not always the best choice. For example, the value of the option will be $29.4 \$$ at the node $\mathrm{F}$ if the vulnerable groups performed the option. However, if the vulnerable groups choose to hold the option rather than perform, the value will be $47.67 \$\left((0.5823 \times 16.97+0.4177 \times 92.38) \times \mathrm{e}^{-0.1 \times 0.1667}=\right.$ 47.67\$).

From the above, we can know that the vulnerable groups can make decisions through the binomial tree option pricing model. They can choose to perform or hold the option to protect their interest.

\section{Conclusion}

The paper tries to construct the market mechanism which can make the vulnerable people involved in the emission trading. The vulnerable people can buy the emission American put option in the emission trading market. When the price of the emission runs below the contract price, the vulnerable people can get the benefit through executing the option. When the price of the emission runs above the contract price, the vulnerable people can give up the right. The binomial tree option pricing model can help the vulnerable people to make decision through the analysis of the worth of the American put option.

\section{Acknowledgements}

This study was partly supported by National Social Science Foundation of China (13CGL095), Major Program of National Social Science Foundation of China (41271537), and the Fundamental Research Funds for the Central Universities (2014B 20014).

\section{References}

[1] Zhou, J.C. (2009) Construct of China’s Rural Social Assistance System for the Victims of Water Pollution. Ecological 
Economy, 219, 157-159.

[2] Wang, H., Dang, L.W. and Wang, L. (2006) Some Thoughts on China’s Water Rights System. China Water Resources, 1, 28-30.

[3] Barnes, A.P., Willock, J., Hall, C. and Toma, L. (2009) Farmer Perspectives and Practices Regarding Water Pollution Control Programmes in Scotland. Agricultural Water Management, 9, 1715-1722. http://dx.doi.org/10.1016/j.agwat.2009.07.002

[4] Clark, A., Turner, T., Dorothy, K.P., Goutham, J., Kalavati, C. and Rajanna, B. (2003) Health Hazards due to pollution of Waters along the Coast of Visakhapatnam, East Coast of India. Ecotoxicology and Environmental Safety, 56, 390397. http://dx.doi.org/10.1016/S0147-6513(03)00098-8

[5] Chen, Y.P. and Wu, F.-P. (2010) Analysis on Conflicts of Initial Water Rights Allocation Based on Evolutionary Game. China Population, Resources and Environment, 20, 48-57.

[6] Azizullah, A., Khattak, M.N.K., Richter, P. and Häder, D.-P. (2011) Water Pollution in Pakistan and Its Impact on Public Health-A Review. Environment International, 37, 479-497. http://dx.doi.org/10.1016/j.envint.2010.10.007

[7] Shen, D.J. (2005) On the Unjust Issues of Water Management in China. Journal of Hydraulic Engineering, 1, 95-99.

[8] Xu, G.H. and Guo, S.L. (2007) Inter-Provincial Water Disputes and Countermeasures in Yangtze River Basin. Water Resources Protection, 2, 54-56.

[9] Sakai, H., Iiyama, S. and Toko, K. (2000) Evaluation of Water Quality and Pollution Using Multichannel Sensors. Sensors and Actuators, 66, 251-255. http://dx.doi.org/10.1016/S0925-4005(00)00383-X

[10] Dong, W.F. and Li, X.B. (2006) Analysis of Water Resource of Miyun Reservoirin Chaobai River Basin. Environmental Science \& Technology, 29, 57-60. 